\title{
View Insulin Resistance from an Interaction Between Pancreatic Islets and Peripheral Tissues
}

\author{
Ming Li ${ }^{1, ~ *, ~ Y o u ~ L u ~}{ }^{1}$, Alun Rongxiang Wang ${ }^{2}$ \\ ${ }^{1}$ Department of Physiology, Tulane University, New Orleans, USA \\ ${ }^{2}$ Department of Pathology, Tulane University, New Orleans, USA
}

Email address:

mli@tulane.edu (Ming Li), ylu6@tulane.edu (You Lu), awang2@tulane.edu (A. R. Wang)

${ }^{*}$ Corresponding author

\section{To cite this article:}

Ming Li, You Lu, Alun Rongxiang Wang. View Insulin Resistance from an Interaction Between Pancreatic Islets and Peripheral Tissues. Clinical Medicine Research. Vol. 7, No. 5, 2018, pp. 124-130. doi: 10.11648/j.cmr.20180705.14

Received: August 20, 2018; Accepted: October 30, 2018; Published: November 26, 2018

\begin{abstract}
Curl rent hypotheses of insulin resistance mostly emphasize cellular mechanisms in peripheral tissues. Although received broad recognition, these opinions may have overlooked the interaction between pancreatic endocrine cells and the peripheral tissues in the process of establishment and maintenance of insulin resistance in the whole body. It has been suggested that basal hyperinsulinemia is the root cause of insulin resistance. Basal insulin release does not share the same intracellular mechanism of high glucose stimulated insulin release; instead, it is regulated by local $\mathrm{Ca}^{2+}$ fluctuation and activation of the cAMP-Epac2/Rap1 signaling pathway. Basal insulin release is controlled by the interaction between pancreatic head $\beta$-cells and pancreatic tail $\alpha$-cells, which release insulin and glucagon, respectively. In diabetes, an elevated basal insulin level would mitigate the sensitivity of peripheral tissues to insulin; the decreased insulin sensitivity and elevated plasma glucose concentration could further stimulate more basal insulin release partially by increasing T-type $\mathrm{Ca}^{2+}$ channel expression and activity in $\beta$-cells. This interaction forms a positive feedback loop. Therefore, $\mathrm{T}$-type $\mathrm{Ca}^{2+}$ channel antagonists can potentially be employed to break this positive feedback loop, thus reversing insulin resistance.
\end{abstract}

Keywords: Insulin Resistance, Hyperinsulinemia, T-type $\mathrm{Ca}^{2+}$ Channel

\section{Introduction}

One decade ago, it was estimated that the prevalence of diabetes patients would increase from 171 million to 366 million by 2030 globally [1]. In fact, the number of diagnosed diabetic patients was over 422 million in 2014 [2]. Although advanced biomedical sciences brought a bright future to medicine in general, the diabetes epidemic dramatically increased worldwide. More importantly, drugs that were developed for treating diabetes could only slow down the progression of the disease, rather than reverse it. It would be worthwhile to review the mechanism of insulin resistance in diabetes and to identify potential new targets for fighting the disease.

Unlike cancer, most animals on the earth do not have diabetes. In humans, diabetes had been a historically rare disease, due to the lack of sufficient food supplies, and the short of lifespan. In 1900, the average life expectancy of a human was 31, globally. However, in 2015, the average lifespan for a human being has increased to 70.5 years [3]. The change of average life expectancy was not only because of advanced health care, but sufficient intake of nutrients from daily diet. It is Human genes that aim to adapt the hunger status evolved from hundred thousand years ago, to let us store all nutrients acquired. For example, the kidney reabsorbs $100 \%$ glucose from filtrate. These "hunger" genes are now facing an unprecedented challenge of excessive intake of nutrients which cannot be disposed appropriately. Thus, the pathogenesis of type 2 diabetes is directly associated with excessive intake of nutrients which causes unbalanced glucose homeostasis.

\section{Insulin Resistance}

In the human body, combustion of biofuels such as glucose, fat, and amino acids requires insulin. Elevation of blood glucose levels signals pancreatic $\beta$-cells to secrete 
insulin, which travel to the insulin receptors on muscle, liver and adipose tissue to turn on glucose metabolic processes. Insulin works as a key to open the doors of muscle and fat cells allowing uptake of glucose. Under fasting condition, blood insulin remains at a low level to restrict the use of glucose by muscle and fat cells so that the brain gets priority in using the available glucose supply. For prediabetic subjects and early phase type 2 diabetic patients, however, the response by muscle and fat cells to insulin decreases and the insulin levels are compensatively elevated. This phenomenon is known as peripheral tissue insulin resistance, which is also associated with cardiovascular disease and metabolic disorders, including hypertension, hyperlipidemia, atherosclerosis and polycystic ovarian syndrome [4].

In addition to insulin resistance, obesity is another risk factor of type 2 diabetes and it correlates with insulin resistance $[5,6]$. Although obesity is associated with insulin resistance, most obese people with insulin resistance do not develop hyperglycemia. This is due to an extra secretion of insulin that compensates the effect of insulin resistance. Up to date, no drug can effectively reverse or halt the progress of insulin resistance. The United Kingdom Prospective Diabetes Study (UKPDS) suggested that after ten years follow-up on five thousand pre-diabetic patients, the progress of elevating the hemoglobin $\mathrm{A}_{1 \mathrm{c}}(\mathrm{HbA1c})$ cannot be stopped regardless applying many types of drug treatments, including sulfonylureas, metformin, and intensive insulin therapy [7]. As shown in Figure 1, the disease progression curves of drug treatment and dietary control plus exercises are parallel ones, suggesting that the drugs or direct insulin injection delayed the onset but failed to alter the rate of progression of diabetes.

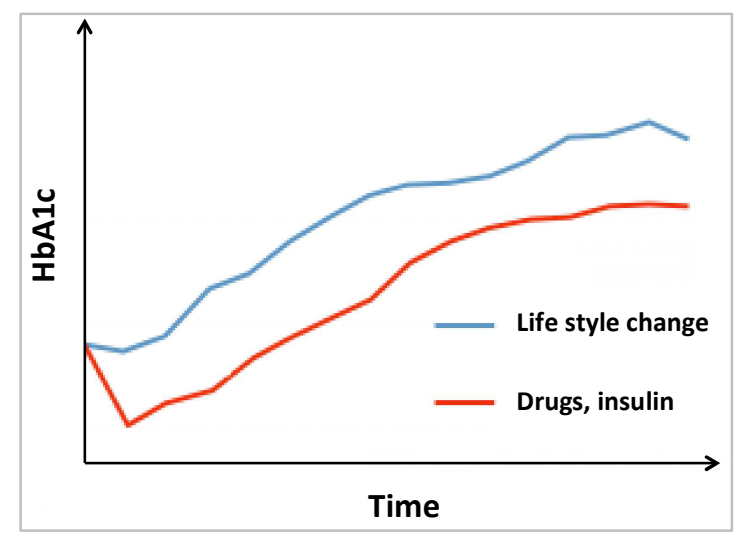

Figure 1. The influences of drug, insulin, life style changes on HbAlc levels during a long-term cohort study (reconstructed from UK Prospective Diabetes Study (UKPDS) Group, Lancet 1998:352:837-853).

The concept of insulin resistance includes decrease in insulin sensitivity, responsiveness, or both [8]. Decrease in insulin sensitivity can be observed in both diabetic and nondiabetic subjects, in nondiabetic subjects who have insulin insensitivity, the equivalent glucose uptake can be achieved by increasing the circulating insulin concentration, as seen in those who are hyperinsulinemic but normoglycemic. In contrast, the decrease in insulin responsiveness is observed only in hyperglycemic subjects, whose maximal glucose uptake is significantly reduced regardless of high insulin level.

Insulin sensitivity is a function of insulin concentration. Muscle and fat tissue have developed an impediment mechanism (insensitivity) for insulin's function so that they would not drain out glucose from blood when insulin concentration is high. Data from clinical analysis indicate that sensitivity of insulin receptor is reversely proportionate to plasma insulin concentration. The relationship between insulin production and insulin sensitivity can be approximately simulated by a hyperbolic function as shown in Figure 2 [9]. Under the condition of chronic elevated basal insulin level (such as in prediabetic and diabetic individuals), the cellular mechanism of insulin insensitivity becomes exaggerated, thus leading to insulin resistance.

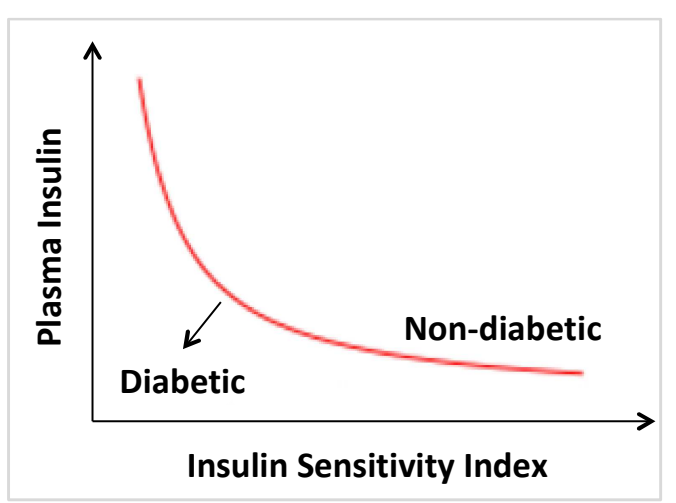

Figure 2. Relationship between peripheral insulin sensitivity and B-cell insulin production.

The cellular mechanism of insulin insensitivity includes a decreased number of insulin receptor on cell surfaces [10] and reduced translocation of glucose transporter IV (Glut 4) to the plasma membrane [11]. This type of insulin resistance is also observed in obese nondiabetic subjects, which can be explained by the hyperbolic relationship curve in Figure 2. In the case of type 2 diabetes, following the reduction of insulin release, blood glucose is elevated. A second component of insulin resistance (reduction of insulin responsiveness) is introduced by hyperglycemia [12]. The mechanism of insulin irresponsiveness might include receptor kinase function and kinetic change in glucose disposal [13]. This component combined with a defect of insulin release pulls the hyperbolic curve in the figure 2 downward to the origin [14].

The hyperbolic relationship between insulin production and sensitivity indicates that boosting insulin secretion is useful for lowering the plasma glucose but it does not benefit on recovering insulin sensitivity. It also suggests that maintaining chronic basal hyperinsulinemia would facilitate a progression of insulin resistance, as seen in nondiabetic insulin resistant subjects. Whether or not chronic hyperinsulinemia would facilitate insulin non-responsiveness is not known, but the fact that $2-6 \%$ of insulin resistant subjects progress to type 2 diabetes every year [15] suggests there may be a connection between the two. 


\section{Current Theories of Insulin Resistance and Their Challenges}

Two common hypotheses (fat overload and inflammation) anchor initiation of insulin resistance to the accumulation of adipose tissue. The first one considers the lipid metabolism. Rising level of intracellular fatty acid metabolites, such as diacylglycerol (DAG) and fatty acyl-CoAs activates PKC- $\theta$ and increases Ser312 phosphorylation of IRS-1, this slows down Tyr612 and other sites of tyrosine phosphorylation, thus decreasing Phosphatidylinositol-4,5-bisphosphate 3kinase (PI3K) activity and inhibiting insulin signaling [16]. The other hypothesis proposes enlarged fat cells attract macrophages and excrete inflammatory cytokines (i.e. interleukin-1 $\beta$ (IL-1 $\beta)$, tumor necrosis factor- $\alpha$ (TNF- $\alpha)$ and interleukin-6 (IL-6), etc.) that work at muscle cells. These inflammatory cytokines inhibit IRS-1 by activate c-Jun Nterminal kinase (JNK), via similar serine-tyrosine phosphorylation interactive mechanism [17]. Both hypotheses try to establish a causal relationship between obesity/lipid overload and insulin resistance. Nevertheless, neither of them could explain neatly why a third of obese people are free of insulin resistance [18], and why 30-80\% type 2 diabetic patients in different cultures are not obese [19].

Furthermore, these hypotheses could not account a rapid remission of type 2 diabetes seen from bariatric surgeries, in which remission starts a few days to weeks after the operation, long before any significant weight loss [20]. If the pathogenesis were derived from fatty acids or cytokines accumulation due to obesity, it would be expected to see a positive relationship between the weight lost and the remission from type 2 diabetes. The onset of remission is shorter than it takes for significant weight lost from surgery. Therefore, the adipose hypotheses might only partially explain the cause of insulin resistance. Alternatively, it could be postulated that a hormone-like factor plays a key role in inducing insulin resistance. The function of the factor is enhanced by chronic food over consumption and is disrupted by bariatric surgeries [21]. The merit of introducing hormone-like factor for the pathogenesis of diabetes is that it is easier to explain the instant effects of bariatric surgery, as well as the discordance between body weight and severity of diabetes. However, no evidence of such a factor yet exists.

\subsection{Basal Hyperinsulinemia Caused Insulin Resistance}

The effect of bariatric surgeries on type 2 diabetes mellitus remission strongly suggests a whole body regulating mechanism is involved in insulin function and production. What factors would affect both peripheral insulin sensitivity and insulin production from pancreatic $\beta$-cells? It could be any of the circulating hormonal or non-hormonal insulin antagonists or a combination of them. Based upon the hyperbolic inhibitory curve between insulin sensitivity and insulin production, it is likely that insulin itself is such an antagonist. Barbara Corkey has proposed that: "basal hyperinsulinemia is the root cause of insulin resistance, obesity, and diabetes" [22]. Obese subjects with high basal insulin level would have reduced insulin sensitivity and end up with insulin resistance. Similarly, diabetic patients who have a defect in glucose stimulated insulin secretion and basal hyperinsulinemia would also have insulin resistance. The basal hyperinsulinemia hypothesis is also supported by the fact that an increased insulin secretion occurs before insulin resistance [23, 24]. More importantly, the concept of interactions between peripheral tissues and $\beta$-cells has been introduced by this hypothesis to better describe the mechanism behind insulin resistance.

Following the hypothesis that basal hyperinsulinemia leads to insulin resistance, we next face questions: What is the cause of basal hyperinsulinemia? How is basal hyperinsulinemia regulated? How to reduce basal insulin secretion?

It has been suggested that environmental and genetic factors may cause basal hyperinsulinemia, via changing oxidization-reduction processes in $\beta$-cells and others [25, 14]. For example obese and diabetic patients have higher lactate versus pyruvate $(\mathrm{L} / \mathrm{P})$ and $\beta$-hydroxybutyrate versus acetoacetate $(\beta / \mathrm{A})$ ratio $[25,26]$ as well as increased production of free radicals, all can cause extra secretion of insulin [22]. However, it is unclear which specific environmental or genetic factors induce the defective oxidation-reduction processes and how these factors relate to over nutritional status in diabetes.

The operation of basal insulin secretion is largely unknown. It may be useful to look at the process of glucose stimulus-secretion, which may provide hints for understanding the mechanism of basal insulin secretion. As shown in Figure 3, glucose enters into $\beta$-cell via glucose transport II (Glut2), and then gets oxidized in mitochondria to produce ATP. An increased ATP/ADP ratio forces closing of ATP sensitive potassium channels, led to depolarize cell membrane. Subsequently, voltage-dependent L-type of calcium channels on cell membrane would open to raise intracellular calcium ion concentration. Calcium ions then trigger a fusion of insulin granules and plasma membrane and insulin secretion ensues [27]. Statistically, over ten thousand of insulin granules have been found in a $\beta$-cell with an average 200 nanometers of granule diameters. This means that the $\beta$-cell is fully packed by granules like a pomegranate. Only 700 to 1000 granules are attached to cell membrane and are referred to as in the docked pool. Inside the docked granules, merely 50 to 100 granules are following into the priming status $[28,20]$. Upon reaching a high level of glucose stimulus (postprandial), primed granule releases its insulin content in a rate of one granule per every five or six seconds. This process is the mechanism of the first phase of insulin secretion, which lasts about 10 to 15 minutes. After that, a slower second phase of insulin secretion starts and lasts for 120 minutes. Type 2 diabetes mellitus is characterized by a disappearance of the first phase but not the second phase [29, 30]. 


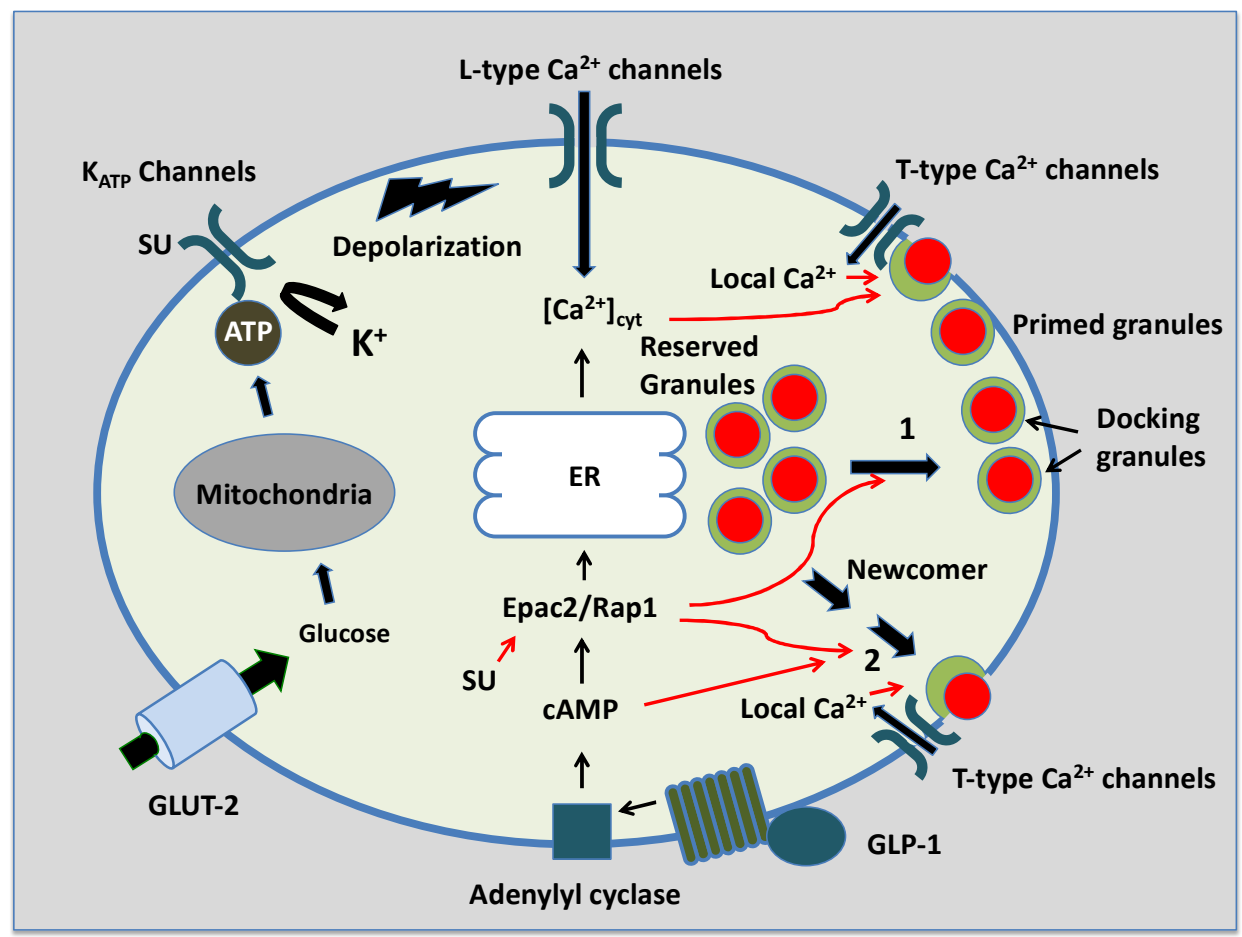

Figure 3. Regulation pathways of Insulin secretion in a pancreatic $\beta$-cell.

Since basal insulin secretion is independent of glucose stimulus, its secretion would rely on a pathway other than glucose triggered L-type calcium channel dependent insulin secretion pathway. Nevertheless, priming granules require calcium flux for releasing insulin. So, the question becomes what are the sources of calcium ions? It could come from intracellular high calcium reservoirs, such as the endoplasmic reticulum, endosome [31], voltage-independent calcium channels on the plasma membrane, or other non-selective channels. Since basal insulin secretion is a slow process that in theory requires only a slight local elevation of calcium ion concentration, all of these pathways could be used as calcium sources. Nevertheless, one pathway in particular, the T-type calcium channel would be an attractive candidate as an explanation for facilitating basal insulin release and is discussed below.

\subsection{Function of T-type Calcium Channels}

Typically, in physiology, voltage-dependent channels can be categorized as $\mathrm{L}, \mathrm{N}, \mathrm{T}, \mathrm{P} / \mathrm{Q}, \mathrm{R} / \mathrm{E}$ etc. Only the T type is a low-voltage gated channel. Without glucose stimulus, the Ttype of calcium channel on $\beta$-cells could be opened partially [32]. Functions of T-type calcium channel mediated hormone and neurotransmitter release under non-stimulus conditions have been intensely studied [33-36]. Calcium influx through T-type calcium channels would contribute to elevating basal calcium concentration and increasing the frequency of random calcium spikes [37], as well as increasing the rate of spontaneous membrane depolarization, which may transiently trigger L-type calcium activity [38], thus elevating restricted area calcium concentration. Therefore, expression and activation of T-type of calcium channel can facilitate basal insulin secretion.

The function of T-type calcium channels in $\beta$-cells can be regulated under the peripheral insulin resistant conditions. It has been shown that expression of T-type calcium channels in $\beta$-cells is increased by interferon- $\gamma$, interleukin $1-\beta$ and tumor necrosis factor- $\alpha$ [39]. Additionally, chronic elevation of glucose also increases T-type calcium channel expression in $\beta$-cells [37]. These results indicate that up-regulation of Ttype calcium channel may be associated with a progression of insulin resistance in the peripheral tissues via chronic basal hyperinsulinemia. This completes a positive feedback loop between peripheral tissue and pancreatic $\beta$-cells in insulin resistance.

Furthermore, elevation of basal calcium concentration mediated by T-type calcium channels will effectively result in $\beta$-cell L-type calcium channels internalization and make them abstain during glucose stimulated membrane depolarization [40]. This could partially explain the defect of glucose stimulated insulin release in type 2 diabetes mellitus. Since hyperglycemia is a causative component of insulin irresponsibleness, T-type calcium channels may therefore be involved in the interaction between $\beta$-cell function and peripheral insulin resistance.

\section{3. cAMP Pathway Involves in Basal Insulin Secretion}

Free fatty acid (FFA) is another factor that causes insulin resistance. Studies have shown that basal insulin secretion could be increased by FFAs [41-43]. In addition, by binding onto their receptors on the $\beta$-cell membrane, FFAs acting on $\mathrm{L}$ cells in the small intestine trigger a release of glucagon-like peptide-1 (GLP-1). As shown in Figure 3, when GLP-1 binds to the receptors on the $\beta$-cell membrane, it activates adenylyl 
cyclase [44] and generates cAMP $[45,46]$. cAMP will then regulate exchange protein activated by cAMP-2 (Epac2/Rap1) to increase the release of intracellular calcium [47]. Epac2 will further facilitate trafficking of the granules from reserved pool to pre-docked pool [48]. In addition cAMP/Epac2 activated insulin granules may translocate to the cell membrane and release insulin immediately $[49,50]$. This is called "restless newcomer" mechanism, which bypasses the priming stage and may play a significant role in basal insulin secretion.

The Epac2/Rap1 signaling pathway can also up-regulate expression and synthesis of T-type calcium channels [51]. Therefore, FFAs, inflammatory cytokines and chronic hyperglycemia all exhibit positive effects on the increased expression of T-type calcium channels. As shown in Figure 4 , peripheral insulin resistance can trigger the upregulation of T-type calcium channel on $\beta$-cell, resulting in raised basal insulin secretion, which in turn acts on peripheral tissues and causes insulin resistance. This positive feedback loop could be developed for progressing into type 2 diabetes mellitus.

If the T-type calcium channel triggered signal pathways are involved in the interaction between insulin resistance and basal insulin secretion; could this positive feedback loop be disrupted by blocking the activity of T-type calcium channels? Indeed, applying T-type calcium channel siRNA, or channel blockers (e.g. mibefradil, NNC 55-0396) to rat islet cells or diabetic mice can reduce the basal insulin level as well as hyperglycemia in these preparations [37, 52].

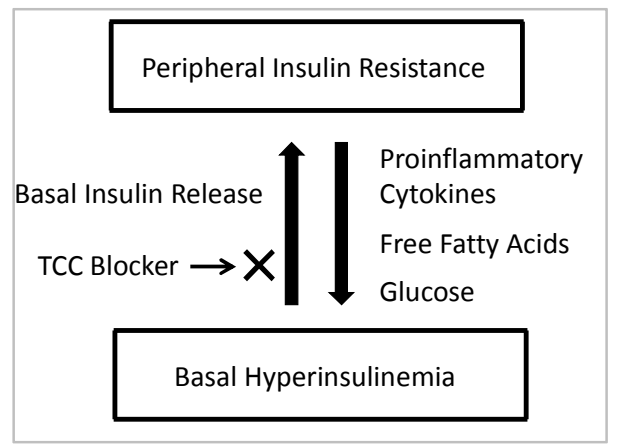

Figure 4. Schematic drawing of positive feedback loop of basal hyperinsulinemia induced insulin resistance.

\section{Conclusions}

Both components of insulin resistance, insulin insensitivity and insulin irresponsiveness, require an interaction between pancreatic $\beta$-cells and peripheral target tissues of insulin. The operation of hyperbolic function between insulin concentration and insulin sensitivity in obese nondiabetic subjects implies the dependency of insulin sensitivity on the insulin production. Basal hyperinsulinemia and uncompensated insulin production to glucose stimulation in combination could be the culprit of insulin resistance in type 2 diabetes mellitus. Interventions that break down the positive feedback loop between islet malfunction and defective peripheral tissues of insulin insensitiveness may ameliorate or even reverse insulin resistance.

\section{References}

[1] Wild S, Roglic G, Green A, Sicree R, King H. Global prevalence of diabetes estimates for the year 2000 and projections for 2030. Diabetes care 2004;27:1047-1053.

[2] Diabetes. World Health Organization. Available at: http://www.who.int/news-room/fact-sheets/detail/diabetes. 2018.

[3] Nations, United. World population prospects: The 2015 revision. United Nations Econ Soc Aff 2015;33:2:1-66.

[4] Reaven GM. Pathophysiology of insulin resistance in human disease. Physiol Rev 1995;75:473-486.

[5] Caspard H, Jabbour S, Hammar N, Fenici P, Sheehan JJ, Kosiborod M. Recent trends in the prevalence of type 2 diabetes and the association with abdominal obesity lead to growing health disparities in the USA: an analysis of the NHANES surveys from 1999 to 2014. Diabetes, Obesity and Metabolism. 2018;20:3:667671.

[6] Cersosimo E, Triplitt C, Solis-Herrera C, Mandarino LJ, DeFronzo RA. Pathogenesis of type 2 diabetes mellitus. 2018;In Endotext [Internet]. MDText. com, Inc.

[7] Group, U. P. D. S., Intensive blood-glucose control with sulphonylureas or insulin compared with conventional treatment and risk of complications in patients with type 2 diabetes (UKPDS 33). The Lancet 1998;352:837-853.

[8] Kahn CR. Insulin resistance, insulin insensitivity, and insulin unresponsiveness: a necessary distinction. Metab Clin Exp 1978;27:1893-1902.

[9] Kahn SE, Prigeon RL, McCulloch DK, Boyko EJ, Bergman RN, Schwartz MW, Neifing JL, Ward WK, Beard JC, Palmer JP. Quantification of the relationship between insulin sensitivity and $\beta$-cell function in human subjects: evidence for a hyperbolic function. Diabetes 1993;42:1663-1672.

[10] Olefsky JM. Lilly lecture 1980: Insulin resistance and insulin action: an in vitro and in vivo perspective. Diabetes 1981;30:148162.

[11] Reno, CM, Puente EC, Sheng Z, Daphna-Iken D, Bree AJ, Routh VH, Kahn BB, Fisher SJ. Brain GLUT4 knockout mice have impaired glucose tolerance, decreased insulin sensitivity, and impaired hypoglycemic counterregulation. Diabetes 2017;66(3):587-597.

[12] Bril F, Cusi K. Basic Concepts in Insulin Resistance and Diabetes Treatment. In Dermatology and Diabetes. 2018;19-35. Springer, Cham.

[13] Müller HK, Kellerer M, Ermel B Mühlhöfer A, ObermaierKusser B, Vogt B, Häring HU. Prevention by protein kinase C inhibitors of glucose-induced insulin-receptor tyrosine kinase resistance in rat fat cells. Diabetes 1991;40:1440-1448.

[14] Kahn SE. The importance of $\beta$-cell failure in the development and progression of type 2 diabetes. J Clin Endocrinol Metab 2001;86:4047-4058.

[15] Alberti KGMM. The clinical implications of impaired glucose tolerance. Diabetic Med 1996;13:927-937.

[16] Shulman GI. Cellular mechanisms of insulin resistance. J Clin Invest 2000;10: 171-176. 
[17] Wellen KE, Hotamisligil GS. Hotamisligil, Inflammation, stress, and diabetes. J Clin Invest 2005;115:1111-1119.

[18] Taubes G. Prosperity's plague. Science 2009;325:256-260.

[19] Colosia AD, Palencia R, Khan S. Prevalence of hypertension and obesity in patients with type 2 diabetes mellitus in observational studies: a systematic literature review. Diabetes Metab Syndr Obes 2013;6:327-38.

[20] Cohen RV, Rubino F, Schiavon C, Cummings DE. Diabetes remission without weight loss following duodenal bypass surgery. Surg Obes Relat Dis 2012;8:e66-e68.

[21] Rubino F, and Gagner M. Potential of surgery for curing type 2 diabetes mellitus. Annals of Surgery 2002;236:554-559.

[22] Corkey BE. Banting lecture 2011 hyperinsulinemia: cause or consequence? Diabetes, 2012;61:4-13.

[23] Reed MA, Pories WJ, Chapman W, Pender J, Bowden R, Barakat H, Gavin TP, Green T, Tapscott ED, Zheng DH, Shankley N, Yieh L, Polidori D, Piccoli SP, Brenner-Gati L, Dohm GL. Roux-en-Y gastric bypass corrects hyperinsulinemia implications for the remission of type 2 diabetes. J Clin Endocrinol Metab 2011; 96:2525-2531.

[24] Destefano Mb, Stern JS, Castonguay TW. Effect of chronic insulin administration on food intake and body weight in rats. Physiol Behav 1991;50:801-806.

[25] Poggi-Travert F, Martin D, de Villemeur TB, Bonnefont JP, Vassault A, Rabier D, Charpentier C, Kamoun P, Munnich A, Saudubray JM. Metabolic intermediates in lactic acidosis: compounds, samples and interpretation. J Inherit Metab Dis 1996;19:478-488.

[26] Laffel L. Ketone bodies: a review of physiology, pathophysiology and application of monitoring to diabetes. Diabetes/Metab Res Rev 1999;15:412-426.

[27] Rorsman R, Eliasson L, Renström E, Gromada J, Barg S, Göpel S. The cell physiology of biphasic insulin secretion. Physiol 2000;15:72-77.

[28] Straub SG, Sharp GWG. Glucose-stimulated signaling pathways in biphasic insulin secretion. Diabetes/Metab Res Rev 2002;18:451-463.

[29] Ward WK, Beard JC, Halter JB, Pfeifer MA, Porte D. Pathophysiology of insulin secretion in non-insulin-dependent diabetes mellitus. Diabetes Care 1984;7:491-502.

[30] Hosker JP, Rudenski AS, Burnett MA, Matthews DR, Turner RC. Similar reduction of first-and second-phase B-cell responses at three different glucose levels in type II diabetes and the effect of gliclazide therapy. Metab 1989;38:767-772.

[31] Hou JCQ, Min L, Pessin JE. Insulin granule biogenesis, trafficking and exocytosis. Vitam Horm 2009;80:473-506.

[32] Li M. Role of T-type $\mathrm{Ca}^{2+}$ channels in basal insulin release. In T-type Calcium Channels in Basic and Clinical Science. Schaffer SW \& Li M (Eds.) 2015, Springer. pp. 137-150.

[33] Ivanov AI, Calabrese RL. Intracellular $\mathrm{Ca}^{2+}$ dynamics during spontaneous and evoked activity of leech heart interneurons: low-threshold $\mathrm{Ca}$ currents and graded synaptic transmission. J Neurosci 2000;20:4930-4943.

[34] Pan ZH, Hu HJ, Perring P, Andrade R. T-type $\mathrm{Ca}^{2+}$ channels mediate neurotransmitter release in retinal bipolar cells.
Neuron 2001;32:89-98.

[35] Carabelli V, Marcantoni A, Comunanza V, Luca AD, Diaz J, Borges R, Carbone E. Chronic hypoxia up-regulates $\alpha 1 \mathrm{H} \mathrm{T-}$ type channels and low-threshold catecholamine secretion in rat chromaffin cells. J Physiol 2007;584:149-165.

[36] Tang AH, Karson MA, Nagode DA, McIntosh JM, Uebele VN, Renger JJ, Klugmann M, Milner TA, Alger BE. Nerve terminal nicotinic acetylcholine receptors initiate quantal gaba release from perisomatic interneurons by activating axonal $\mathrm{T}$ type (Cav3) $\mathrm{Ca}^{2+}$ channels and $\mathrm{Ca}^{2+}$ release from stores. $\mathrm{J}$ Neurosci 2011; 31:13546-13561.

[37] Keyser BM, Taylor JT, Choi SK, Lu Y, Bhattacharjee A, Huang L, Pottle J, Matrougui K, Xu Z, Li M. Role of T-type $\mathrm{Ca}^{2+}$ channels in basal $\left[\mathrm{Ca}^{2+}\right]_{\mathrm{i}}$ regulation and basal insulin secretion in rat islet cells. Curr Trend Endocrinol 2014;7:3544.

[38] Bhattacharjee A, Whitehurst Jr RM, Zhang M, Wang L, Li M. T-type calcium channels facilitate insulin secretion by enhancing general excitability in the insulin-secreting $\beta$-cell line, INS-1. Endocrinol 1997;138:3735-3740.

[39] Wang L, Bhattacharjee A, Fu J, Li M. Abnormally expressed low-voltage-activated calcium channels in $\beta$-cells from NOD mice and a related clonal cell line. Diabetes 1996;45:16781683.

[40] Huang L, Bhattacharjee A, Taylor JT, Zhang M, Keyser BM, Marrero L, Li M. $\left[\mathrm{Ca}^{2+}\right]_{\mathrm{i}}$ regulates trafficking of Cav1.3 ( $\alpha 1 \mathrm{D}$ $\mathrm{Ca}^{2+}$ channel) in insulin-secreting cells. Am J Physiol Cell Physiol 2004;286:213-221.

[41] Vestergaard ET, Jessen N, Møller N, Jørgensen JOL. Acyl ghrelin induces insulin resistance independently of $\mathrm{GH}$, cortisol, and free fatty acids. Sci Rep 2017;7:42706.

[42] Unger RH. Lipotoxicity in the pathogenesis of obesitydependent NIDDM: genetic and clinical implications. Diabetes 1995;44:863-870.

[43] Polonsky KS, Sturis J, Bell GI. Non-insulin-dependent diabetes mellitus - a genetically programmed failure of the beta cell to compensate for insulin resistance. New Eng J Med 1996;334:777-783.

[44] Holz GG, Leech CA, Chepurny OG. New insights concerning the molecular basis for defective glucoregulation in soluble adenylyl cyclase knockout mice. Biochim Biophys Acta-Mol Basis of Dis 2014;1842:2593-2600.

[45] Lee YS, Hee SJ. Glucagon-like peptide-1 receptor agonist and glucagon increase glucose-stimulated insulin secretion in beta cells via distinct adenylyl cyclases. Inter J Med Sci 2018 15;6603 .

[46] Wiggins SV, Steegborn C, Levin RL, Buck J. Pharmacological modulation of the $\mathrm{CO} 2 / \mathrm{HCO} 3-/ \mathrm{pH}-$, calcium-, and ATP-sensing soluble adenylyl. Pharm Therap 2018.

[47] Robichaux III WG, Cheng XD. Intracellular cAMP sensor EPAC: physiology, pathophysiology, and therapeutics. Physiol Rev 2018;98:919-1053.

[48] Mei FC, Cheng XD. Interplay between exchange protein directly activated by cAMP (Epac) and microtubule cytoskeleton. Mol Biosyst 2005;1:325-331. 
[49] Shibasaki T, Takahashi H, Miki T, Sunaga Y, Matsumura K, Yamanaka M, Zhang CL, Tamamoto A, Satoh T, Miyazaki J, Seino S. Essential role of Epac2/Rap1 signaling in regulation of insulin granule dynamics by cAMP. Proc Nat Acad Sci 2007;104:19333-19338.

[50] Zhu D, Xie L, Karimian N, Liang T, Kang Y, Huang YC, Gaisano HY. Munc18c mediates exocytosis of pre-docked and newcomer insulin granules underlying biphasic glucose stimulated insulin secretion in human pancreatic beta-cells. Mol Meta 2015;4:418-426.
[51] Novara M, Baldelli P, Cavallari D, Carabelli V, Giancippoli A, Carbone E. Exposure to cAMP and $\beta$ adrenergic stimulation recruits $\mathrm{CaV} 3 \mathrm{~T}$-type channels in rat chromaffin cells through Epac cAMP-receptor proteins. J Physiol 2004;558:433-449.

[52] Lu YJ, Long M, Zhou SW, Xu ZH, Hu FQ, Li M. Mibefradil reduces blood glucose concentration in $\mathrm{db} / \mathrm{db}$ mice. Clinics 2014;69:61-67. 